\title{
Carcinoma Metastatic
}

\section{to Both Cerebellopontine}

Angles Masquerading

\section{as Acoustic Neuromas}

\begin{abstract}
Metastases to the cerebellopontine angles (CPAs) are rare. Typically, the clinical course is one of rapid onset and progression of cranial nerve deficits. The clinical presentation and course of carcinoma metastatic to the CPAs are reviewed. We report a case of bilateral CPA metastases with a radiographic appearance similar to neurofibromatosis type 2 presenting with rapidly progressive bilateral hearing loss followed by unilateral facial nerve palsy. (Skull Base Surgery, 5(1):27-31, 1995)
\end{abstract}

While metastases to the cerebellopontine angle (CPA) are rare, unilateral metastases from a number of different types of tumors have been reported. These include anaplastic lung carcinoma, adenocarcinoma of the breast, squamous cell cancer from head and neck primaries, lymphoma, melanoma, malignant fibrous mesothelioma and xanthoma, adenocarcinoma of the prostate, and adenocarcinoma of unknown primary. ${ }^{1-7}$ Meningeal carcinomatosis causing sudden bilateral hearing loss has been reported. ${ }^{8}$ We report a case of adenocarcinoma from an unknown primary with nodular metastases to both internal auditory canals and CPAs.

\section{CASE REPORT}

A 69-year-old man developed progressive bilateral simultaneous sensorineural hearing loss 8 months prior to our evaluation, followed 1 month later by a right facial weakness that progressed to complete paralysis over 1 month. Contrast-enhanced computed tomography of the brain and internal auditory canals (IACs) (Fig. 1) 7 months prior to our evaluation showed no lesions, and the patient was referred for possible cochlear implantation.

On examination, he had a complete right facial palsy and was profoundly deaf. His past medical history was unremarkable. The remainder of his cranial nerve examination was normal. Electroneuronography showed no response of his right facial nerve to stimulation.

Gadolinium-enhanced magnetic resonance imaging of the head showed a mass in the right IAC (Fig. 2, A and B) that enhanced with contrast and extended $2.2 \mathrm{~cm}$ into the right CPA, abutting the brain stem and tentorium. A smaller mass in the left IAC (Fig. 2C) extended $1 \mathrm{~cm}$ into the CPA. Surgical excision of the mass in the right CPA was planned.

At the time of his preoperative visit, he had no response to ice-water calorics bilaterally. A preoperative chest $\mathrm{X}$-ray was normal. Because of the rapid course of his symptoms, oral and intravenous contrast-enhanced com-

Skull Base Surgery, Volume 5, Number 1, January 1995 Department of Otolaryngology, Saint Louis University, St. Louis, Missouri (E.W.S.), Department of Pathology, Providence Hospital, Southfield, Michigan (B.R.H.), Michigan Ear Institute, Farmington Hills, Michigan (M.J.L.) Presented at the American Academy of Otolaryngology-Head and Neck Surgery Poster Session, Minneapolis, Minnesota October 2-6, 1993 Reprint requests: Dr. Sargent, Department of Otolaryngology-Head and Neck Surgery, Saint Louis University Health Sciences Center, 3635 Vista Ave. at Grand Blvd., Box 15250, St. Louis, MO 63110-0250 Copyright (C) 1995 by Thieme Medical Publishers, Inc., 381 Park Avenue South, New York, NY 10016. All rights reserved. 


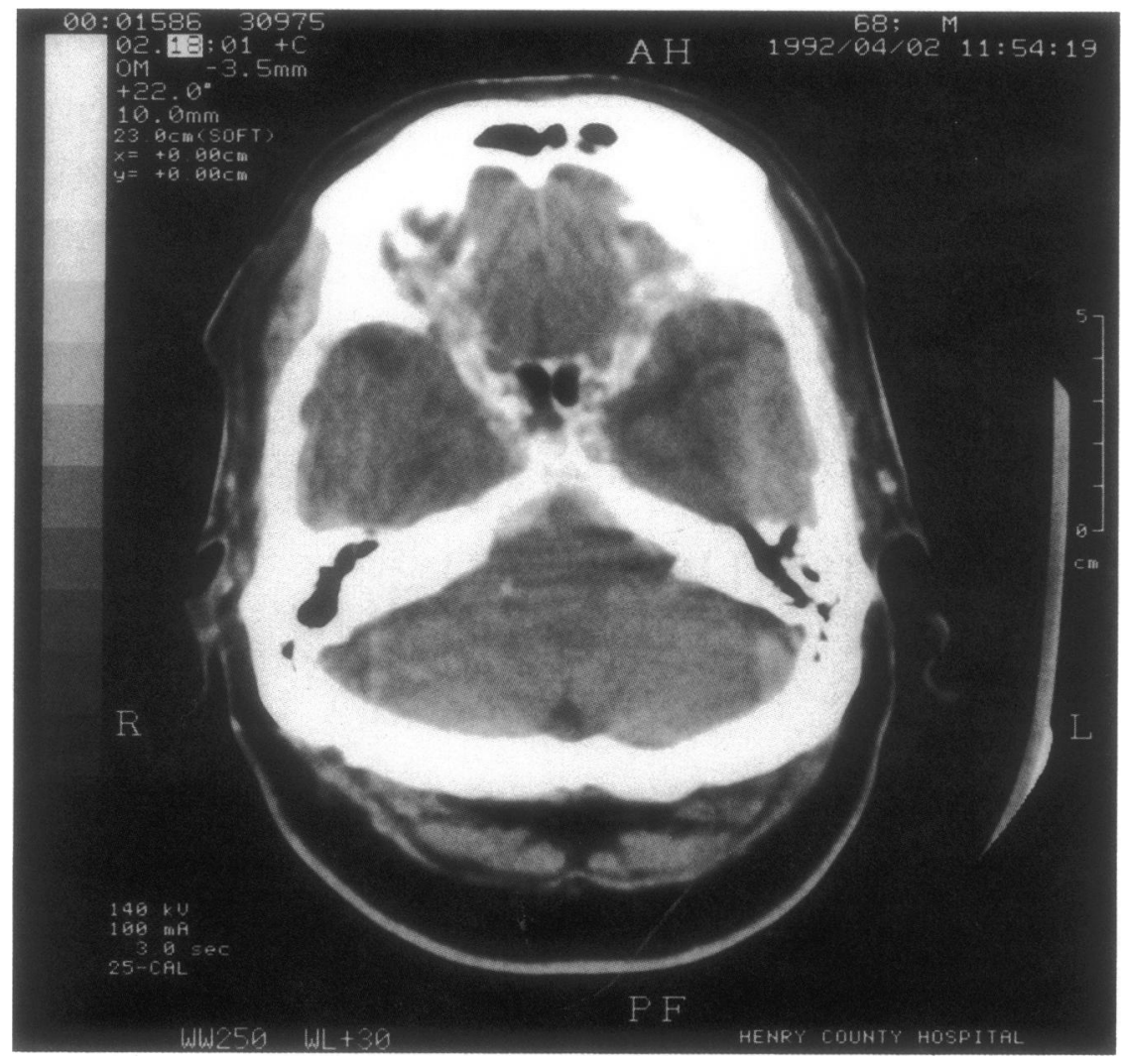

Figure 1. Intravenous contrastenhanced computed tomogram of the brain and internal auditory canals.

puted tomographies of his neck, chest, and abdomen were obtained and showed no evidence of a pulmonary or visceral mass lesion. Carcinoembryonic antigen and prostatespecific antigen levels were within normal limits.

A translabyrinthine approach to the right CPA was performed. Grossly, the tumor appeared pink and was more adherent to adjacent structures than a typical schwannoma. Intraoperative frozen-section analysis revealed carcinoma. Tumor adherent to the brain stem was left in place.

Final pathology of the mass in the right CPA was adenocarcinoma, staining positive for carcinoembryonic

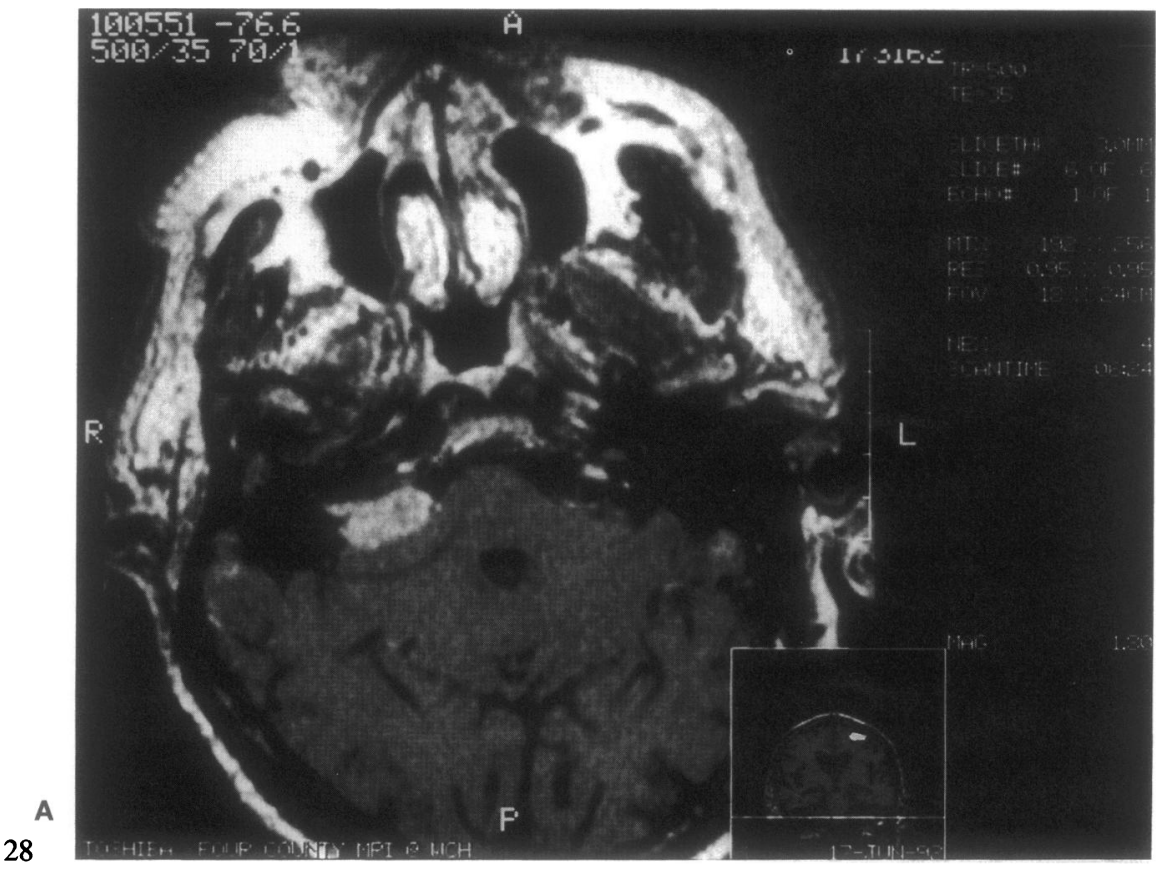

Figure 2. Gadolinium-enhanced magnetic resonance imaging of the brain. A: Axial view of brain stem showing mass in right internal auditory canal (IAC) and cerebellopontine angle (CPA). (Figure continued on the next page.) 
Figure 2. (Continued). B: Coronal view of brain stem and CPA. $C$ : Axial view of brain stem showing mass in left IAC and CPA.
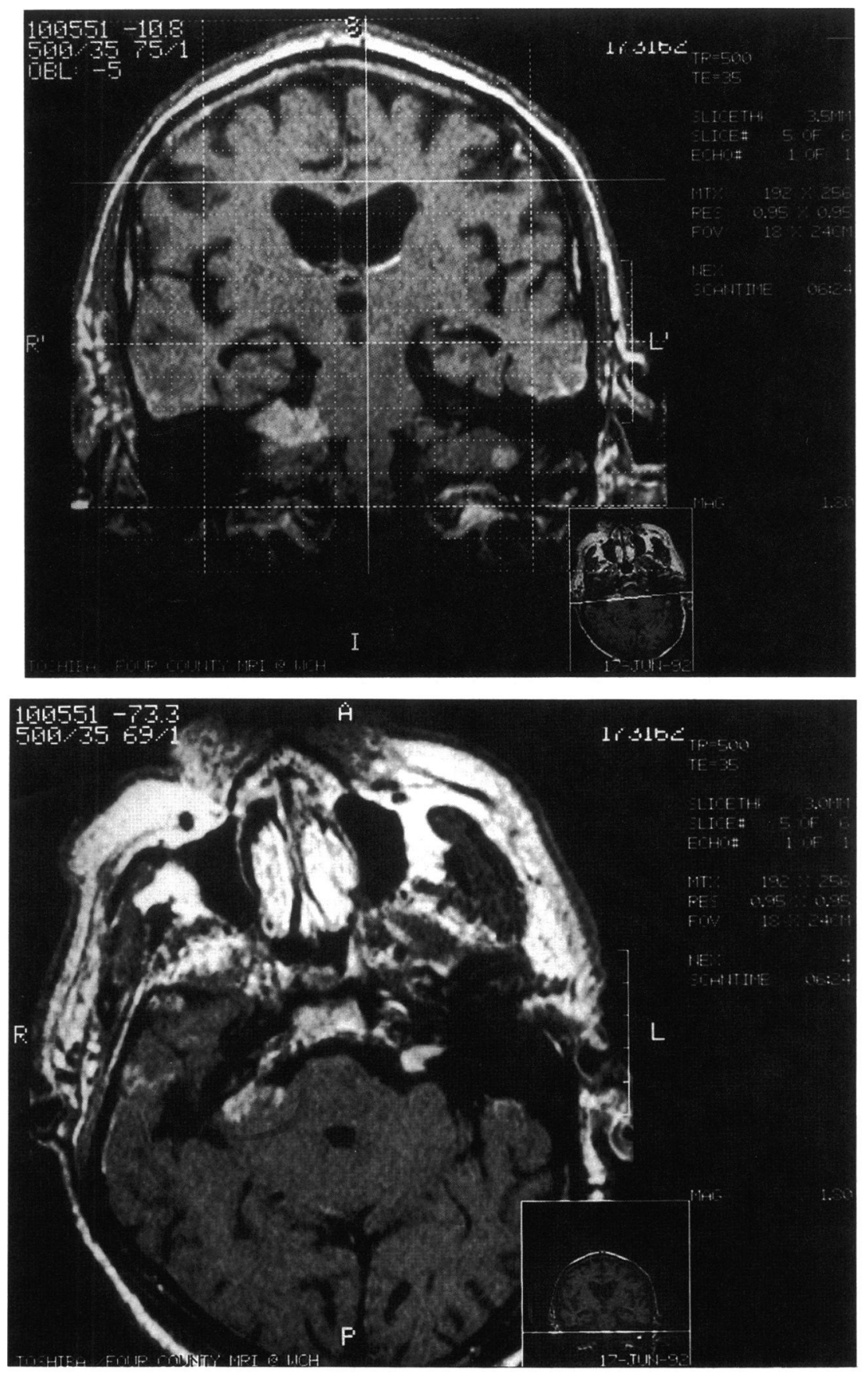

antigen and mucin (Fig. 3). Plans were made for the patient to receive radiation therapy at a hospital near his home, but he died before he could start radiation therapy. At the family's request, an autopsy was not performed.

\section{DISCUSSION}

Metastases presenting as unilateral CPA masses are rare. A review of over 200 tumors occurring in the CPA found only one that was a metastasis. 9

Bilateral malignant metastases with only cranial nerve VII and VIII signs are rare. In fact, despite a thorough search of the literature (including a MEDLINE search), we were unable to uncover a similar case.

Nodular metastases to the CPA represent a variant of leptomeningeal carcinomatosis. Meningeal carcinomatosis can be diagnosed by the appearance of malignant cells in the spinal fluid on cytological examination ${ }^{10,11}$ and has been reported as a cause of hearing loss. ${ }^{12,13}$ As described in a recent report, meningeal carcinomatosis from an esophageal primary caused the abrupt onset of multiple cranial nerve palsies including bilateral hearing loss. ${ }^{8}$ The appearance of metastatic lesions on computed tomogra- 


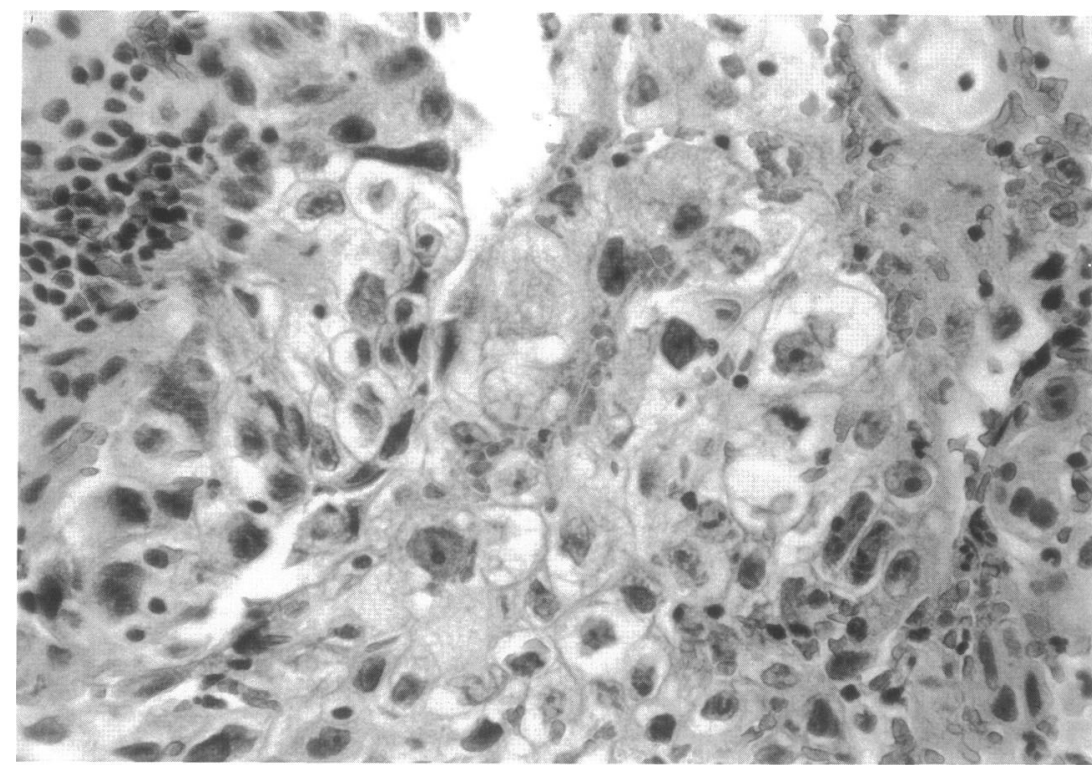

Figure 3. Histological section of cerebellopontine angle mass showing moderately well differentiated adenocarcinoma. Original magnification $\times 450$. phy is variable. Reported enhancement with intravenous contrast because of hypervascularity is not a consistent finding. ${ }^{14}$ In our case, the tumors did not enhance, despite their relatively large sizes.

On magnetic resonance imaging, metastases have a variable appearance. The metastases of our patient appeared identical to acoustic neuromas, with enhancement by intravenous gadolinium on T1-weighted images and a hypointense signal on T2-weighted images. Although edema of adjacent brain parenchyma is occasionally seen in metastasis to the CPA, it was not seen in our case. A suspicious MRI finding in our case suggesting that the lesions were not benign was lack of displacement of the brain stem or tentorium by the mass (Fig. 2B).

The clinical course of our patient was marked by rapid progression of his symptoms, suggesting a malignant process. Furthermore, facial nerve dysfunction, once a presenting sign in $64 \%$ of patients with acoustic neuromas, ${ }^{15}$ is now rarely seen preoperatively, and its presence in this case suggested the possibility of a malignant process. A 1992 study found facial nerve dysfunction in $10 \%$ of patients with acoustic neuromas. ${ }^{16}$ However, nothing in the clinical examination or preoperative work-up identified malignancy. The absence of any cranial nerve palsies in other than the seventh and eighth nerves further confused the picture because lower cranial nerve palsies are common in both nodular metastases to the CPA and meningeal carcinomatosis.

The entity with which this case could be confused radiographically is neurofibromatosis type 2 , an autosomal dominant disorder related to a defect on the long arm of chromosome 22 associated with bilateral nerve sheath tumors of the eighth nerve in the second or third decades. ${ }^{17}$ Our patient, because of the rapid progression of his symptoms as well as his age, was not believed to have neurofibromatosis type 2 .

\section{CONCLUSION}

Bilateral malignant metastases to the CPAs can cause rapidly progressive bilateral hearing loss, vestibular dysfunction, and facial palsy. Radiologically, malignant masses may appear deceptively like benign lesions of the area, such as acoustic neuromas. In these cases, clinical suspicion must guide the approach to the patient. Because neurofibromatosis type 2 , the disorder most likely to cause benign lesions of both CPAs, is unusual in middle-aged or elderly people, a search for a primary lesion should be undertaken preoperatively if clinical examination or history warrants.

\section{REFERENCES}

1. Brackmann DE, Bartels LJ: Rare tumors of the cerebellopontine angle. Otolaryngol Head Neck Surg 88:555-559, 1980

2. Flickinger FW, Yuh WT, Nichols RD, Kemp JD: Solitary prostatic metastasis to the cerebellopontine angle: MR and CT findings. J Comput Assist Tomogr 13:1088-1090, 1989

3. Jahrsdoerfer RA, Sweet DE, Fitz-Hugh GS: Malignant fibrous xanthoma with metastasis to cerebellopontine angle. Arch Otolaryngol 102:117-120, 1976

4. Lee YY, Tien RD, Brner JM, et al: Loculated intracranial leptomeningeal metastases: CT and MR characteristics. AJNR 10: 1171-1179, 1989

5. Moloy PJ, del Junco R, Porter RW, Brackmann DE: Metastasis from an unknown primary presenting as a tumor in the internal auditory meatus. Am J Otol 10:297-300, 1989

6. Nakada T, St. John JN, Knight RT: Solitary metastasis of systemic malignant lymphoma to the cerebellopontine angle. Neuroradiology 24:225-228, 1983

7. Walters JL Jr, Martinez AJ: Malignant fibrous mesotheliomametastatic to brain and liver. Acta Neuropathol (Berl) 33:173177,1975

8. Civantos F, Choi YS, Applebaum EL: Meningeal carcinomatosis producing bilateral sudden hearing loss: a case report. Am J Otol 13:369-371, 1992 
9. Hitselberger WE, Gardner GJ: Other tumors of the cerebellopontine angle. Arch Otolaryngol 88:164-166, 1968

10. Schabet M, Kloeter IJ, Adam T, Heidemann E, Wietholder H: Diagnosis and treatment of meningeal carcinomatosis in ten patients with breast cancer. Eur Neurol 25:403-411, 1986

11. Little JR, Dale AJD, Okazakij H: Meningeal carcinomatosis: clinical manifestations. Arch Neurol 30:138-143, 1974

12. Oshiro H, Perlman HB: Subarachnoid spread of tumors in the labyrinth. Arch Otolaryngol Head Neck Surg 81:328, 1965

13. Alberts MC, Terrence GF: Hearing loss in carcinomatous meningitis. J Laryngol Otol 92:233-241, 1978

14. Lalwani AK: Meningiomas, epidermoids and other nonacoustic tumors of the cerebellopontine angle. Otol Clin N Am 25:707728,1992

15. Olsen A, Horrax G: The symptomatology of acoustic tumors with special reference to atypical features. J Neurosurg 1:371-378, 1944

16. Selesnick SH, Jackler RK, Pitts LW: The changing clinical presentation of acoustic tumors in the MRI era. Laryngoscope 103:431-436, 1993

17. Flexon PB, Nadol JB, Schucknecht HF, Montgomery WW, Martuza RL: Bilateral acoustic neurofibromatosis (neurofibromatosis 2): a disorder distinct from von Recklinghausen's neurofibromatosis (neurofibromatosis 1). Ann Otol Rhinol Laryngol 100:830-834, 1991 